Supporting Information

\title{
Facilitating the Oxygen Evolution Reaction of Lithium Peroxide via Molecular Adsorption
}

\author{
Yang Sun $^{\dagger}$ and Haoshen Zhou ${ }^{*},+\star \star$ \\ ${ }^{\dagger}$ Institute of Energy Technology, National Institute of Advanced Industrial Science and \\ Technology (AIST), 1-1-1 Umezono, Tsukuba, 305-8568, Japan. \\ ¥ College of Engineering and Applied Science, National Laboratory of Solid State \\ Microstructures, Nanjing University, Nanjing, Jiangsu, 210093, P. R. China. \\ Corresponding Author \\ *E-mail: hs.zhou@aist.go.jp
}




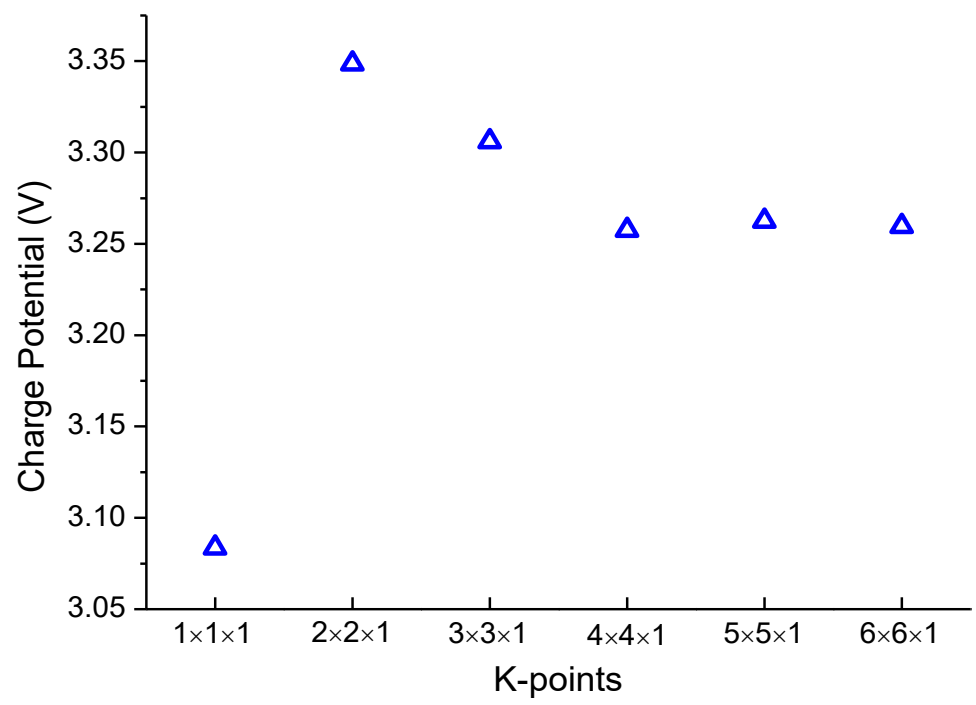

Figure S1. Calculated limiting potential of the $1^{\text {st }} \mathrm{Li}$-extraction on the $\mathrm{Li}_{2} \mathrm{O}_{2}(001)$ surface, with increasing density of k-points. 


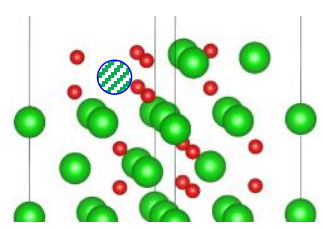

Step 1

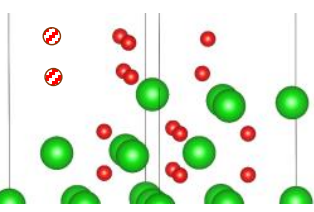

Step 5

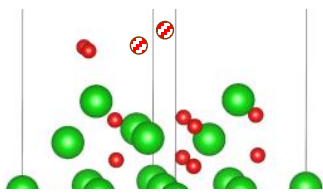

Step 9

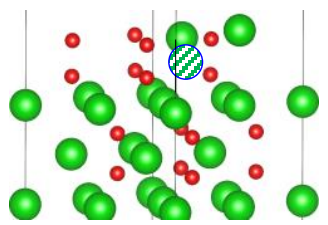

Step 2

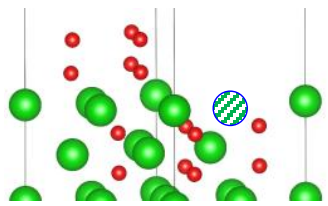

Step 6

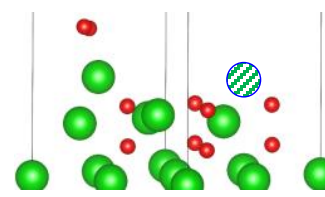

Step 10

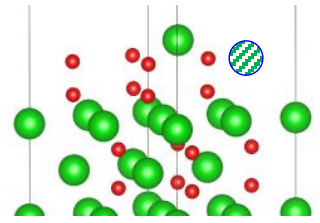

Step 3

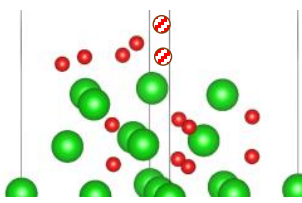

Step 7

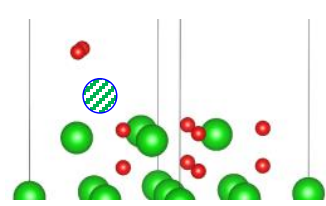

Step 11

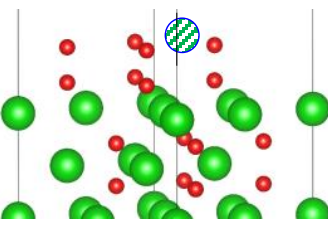

Step 4
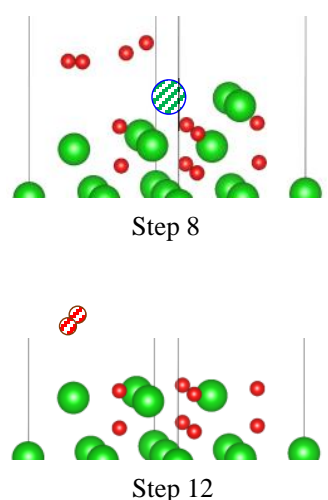

Figure S2. The most energetically favorable conformations of all OER steps occurring on the pristine (001) $\mathrm{Li}_{2} \mathrm{O}_{2}$ surface. $\mathrm{Li}$ and $\mathrm{O}$ atoms are represented by green and red spheres, respectively. The removed atom(s) in the current step is represented by hatched circle(s). 

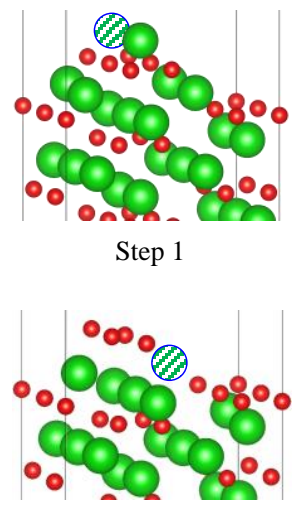

Step 5

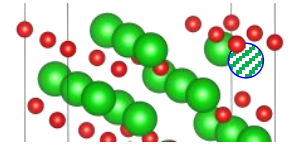

Step 9

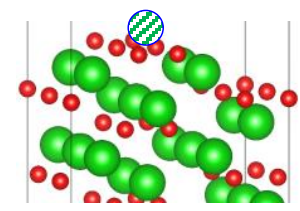

Step 2

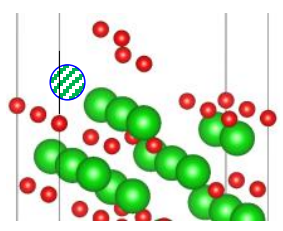

Step 6

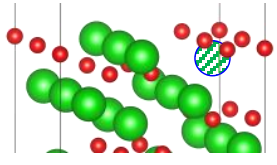

Step 10

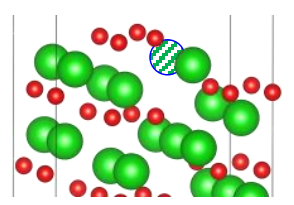

Step 3

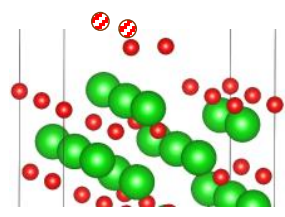

Step 7

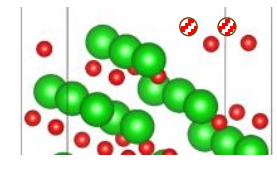

Step 11

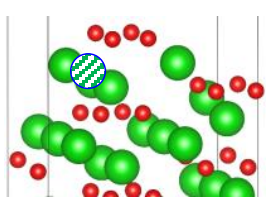

Step 4

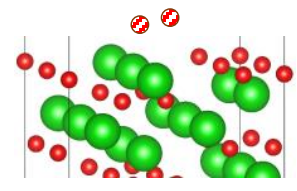

Step 8

Figure S3. The most energetically favorable conformations of all OER steps occurring on the pristine $(1-10) \mathrm{Li}_{2} \mathrm{O}_{2}$ surface. $\mathrm{Li}$ and $\mathrm{O}$ atoms are represented by green and red spheres, respectively. The removed atom(s) in the current step is represented by hatched circle(s). 

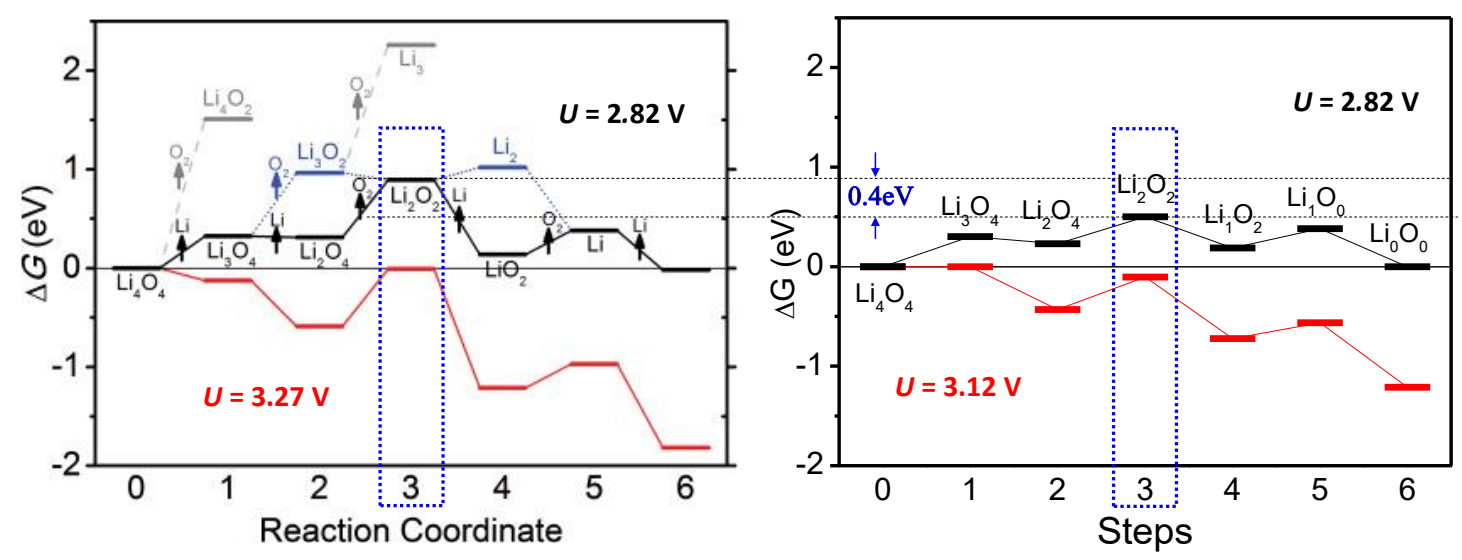

Figure S4. Calculated free energy diagram of OER process on $\mathrm{Li}_{2} \mathrm{O}_{2}(001)$ surface, using the same supercell with that in ref. 1 (dimension of the surface: $3.14 \AA \times 5.22 \AA$ ). According to the results in ref. 1 (left column), the determining step is step-3, i.e., the chemical $\mathrm{O}_{2}$ desorption. However, our results (right column) suggest that the determining step is step-1, corresponding to the electrochemical $\mathrm{Li}$-ion extraction. The qualitative difference is probably due to the insufficient structural relaxation of step3 in ref. 1 ( $0.4 \mathrm{eV}$ higher than the ground state). 


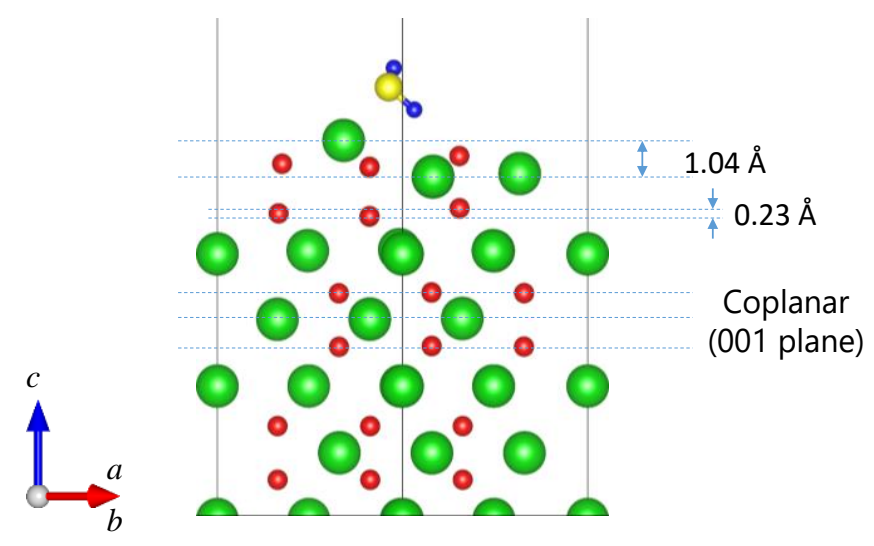

Figure S5. Distortion of the outermost layer after a $\mathrm{H}_{2} \mathrm{O}$ molecule adsorbed on the $\mathrm{Li}_{2} \mathrm{O}_{2}(001)$ surface. $\mathrm{Li}, \mathrm{OLi2O}, \mathrm{H}$, and $\mathrm{O}^{\mathrm{H} 2 \mathrm{O}}$ atoms are represented by green, red, blue, and yellow spheres, respectively. 


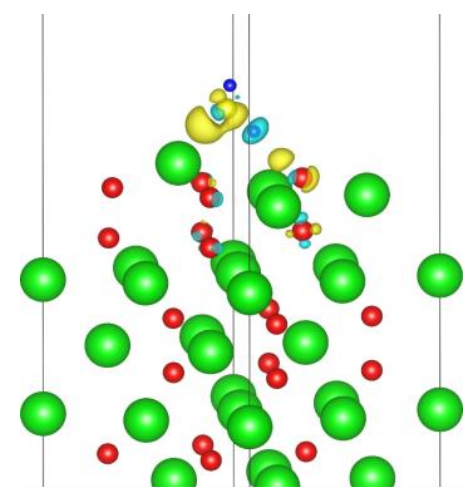

Figure S6. Charge transfer after a $\mathrm{H}_{2} \mathrm{O}$ molecule adsorbed on the $\mathrm{Li}_{2} \mathrm{O}_{2}(001)$ surface. $\mathrm{Li}, \mathrm{O}^{\mathrm{Li} 2 \mathrm{O} 2}, \mathrm{H}$, and $\mathrm{O}^{\mathrm{H} 2 \mathrm{O}}$ atoms are represented by green, red, blue, and yellow spheres, respectively. Isosurface $\left(4.0 \times 10^{-3} \mathrm{e} / \AA^{3}\right)$ : yellow—electron gain, blue-electron loss. 


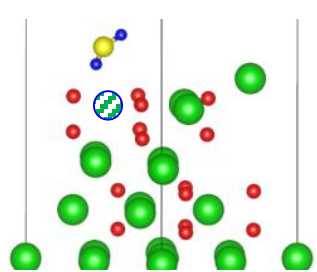

Step 1

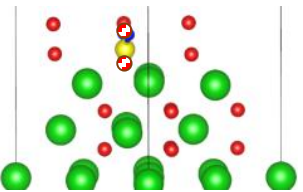

Step 5

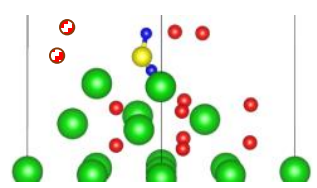

Step 9

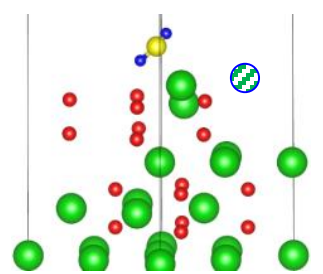

Step 2

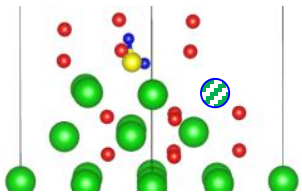

Step 6

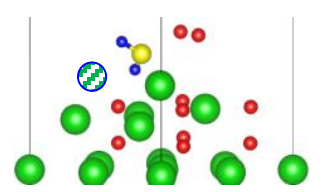

Step 10

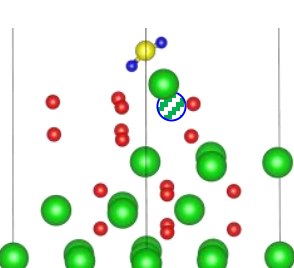

Step 3

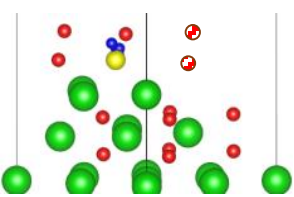

Step 7

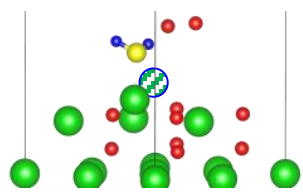

Step 11

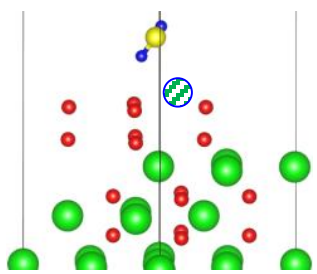

Step 4

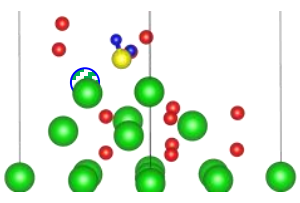

Step 8

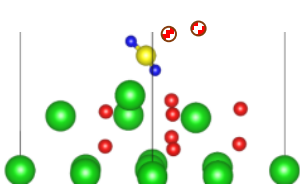

Step 12

Figure S7. The most energetically favorable conformations of all OER steps occurring on the $\mathrm{H}_{2} \mathrm{O}$ molecule adsorbed $\mathrm{Li}_{2} \mathrm{O}_{2}(001)$ surface. $\mathrm{Li}, \mathrm{O}^{\mathrm{Li} 2 \mathrm{O}}$, $\mathrm{H}$, and $\mathrm{O}^{\mathrm{H} 2 \mathrm{O}}$ atoms are represented by green, red, blue, and yellow spheres, respectively. The removed atom(s) in the current step is represented by hatched circle(s). 


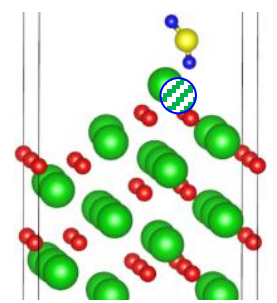

Step 1

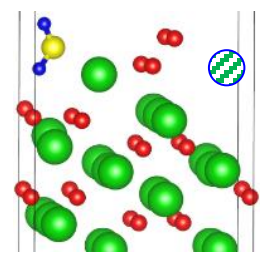

Step 5

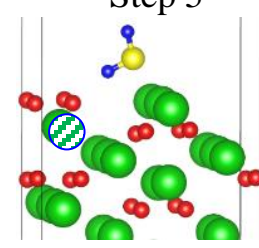

Step 9

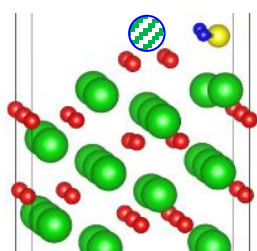

Step 2

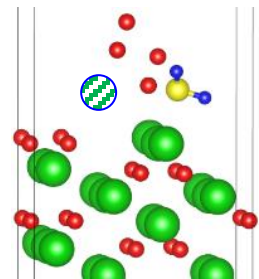

Step 6

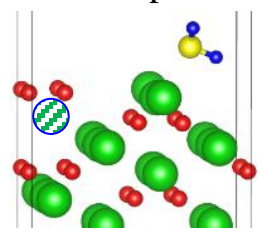

Step 10

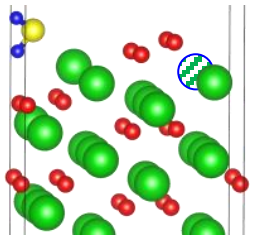

Step 3

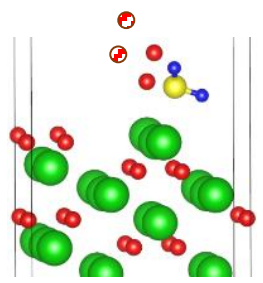

Step 7

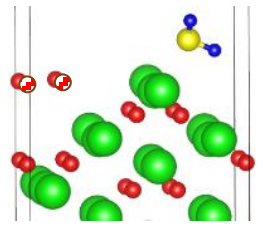

Step 11

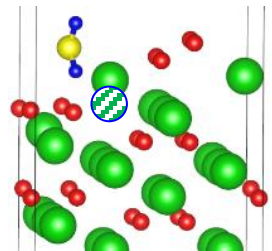

Step 4

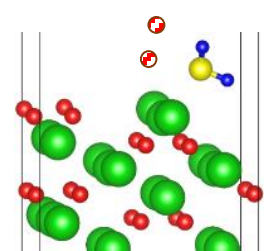

Step 8

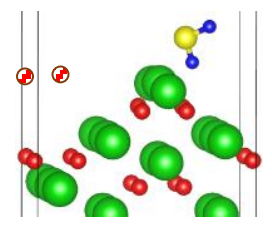

Step 12

Figure S8. The most energetically favorable conformations of all OER steps occurring on the $\mathrm{H}_{2} \mathrm{O}$ molecule adsorbed $\mathrm{Li}_{2} \mathrm{O}_{2}$ (1-10) surface. $\mathrm{Li}, \mathrm{O}^{\mathrm{Li2O}}, \mathrm{H}$, and $\mathrm{O}^{\mathrm{H} 2 \mathrm{O}}$ atoms are represented by green, red, blue, and yellow spheres, respectively. The removed atom(s) in the current step is represented by hatched circle(s). 


\section{Reference}

1. Mo, Y.; Ong, S. P.; Ceder, G. First-principles study of the oxygen evolution reaction of lithium peroxide in the lithium-air battery. Phys. Rev. B 2011, 84 (20), 205446. 